\title{
Bullying e Homofobia: Aproximações Teóricas e Empíricas
}

\author{
Jackeline Maria de Souza \\ Universidade Federal do Vale do São Francisco - Petrolina - PE \\ Joilson Pereira da Silva \\ Universidade Federal de Sergipe - São Cristóvão - SE \\ André Faro \\ Universidade Federal de Sergipe - São Cristóvão - SE
}

\section{Resumo}

Este estudo objetivou verificar como os fenômenos bullying e homofobia se aproximam, comparando a homofobia entre os atores do bullying (autor, alvo, alvo/autor e testemunhas) e observando se o conteúdo homofóbico é utilizado no bullying verbal. Foi realizado um estudo descritivo e quantitativo como método survey. Participaram 808 jovens com idade média de 14,9 anos (DP =1,98), oriundos de 9escolas estaduais de Aracaju-SE, que responderam a um questionário contendo questões sociodemográficas sobre bullying e uma escala de homofobia manifesta e sutil. Os resultados indicaram que $32 \%$ se definiram alvos de bullying, $12 \%$ autores, $22 \%$ alvos/autores e $34 \%$ somente testemunhas. A presença de conteúdo homofóbico no bullying verbal foi a segunda forma mais recorrente entre os participantes do sexo masculino (20\%), tendo menor incidência entre as meninas (2\%). Além disso, os adolescentes autores de bullying apresentaram maiores escores na escala de homofobia, se comparados aos alvos $(p<0,05)$.

Palavras-chave: Bullying; homofobia; adolescentes.

\section{Bullying and Homophobia: Theoretical and Empirical Approaches}

\begin{abstract}
This study aimed at verifying how the phenomena bullying and homophobia approach, comparing homophobia bullying among actors (author, target, target / authors and witnesses) and observing the homophobic content is used in verbal bullying. A descriptive and quantitative study with survey method was performed. 808 young people participated with an average age of 14.9 years $(\mathrm{SD}=1.98)$, coming from nine state schools in Aracaju-SE. They answered a questionnaire containing demographic questions, about bullying, homophobia and a scale manifest and subtle. The results indicated that $32 \%$ were defined targets of bullying, $12 \%$ authors, $22 \%$ target $/$ authors and only $34 \%$ of controls. The presence of homophobic content in verbal bullying was the second most frequent form among male participants (20\%) and lower incidence among girls (2\%). In addition, bullies adolescents had higher scores on the scale of homophobia, compared to targets $(p<0.05)$.
\end{abstract}

Keywords: Bullying; homophobia; teenager.

\section{Bullying y Homofobia: Aproximaciones Teóricas y Empíricas}

\section{Resumen}

Este estudio tuvo por objetivo verificar cómo los fenómenos bullying y homofobia se acercan, comparando la homofobia entre los actores del bullying (autor, diana, diana/autor y testigos) y observando si el contenido homofóbico es utilizado en el bullying verbal. Se realizó un estudio descriptivo y cuantitativo como método survey. Participaron 808 jóvenes con edad media de 14,9 años (DP = 1,98), oriundos de 9 escuelas estaduales de Aracaju-SE, que respondieron a un cuestionario que contenía cuestiones sociodemográficas sobre bullying y una escala de homofobia manifiesta y sutil. Los resultados indicaron que el $32 \%$ se definieron dianas de bullying, el $12 \%$ autores, el $22 \%$ dianas/autores y el $34 \%$ solamente testigos. La presencia de contenido homofóbico en el bullying verbal fue la segunda forma más frecuente entre los participantes del sexo masculino (el 20\%), teniendo menos incidencia entre las niñas (el $2 \%$ ). Además de eso, os adolescentes autores de bullying presentaron mayores escores en la escala de homofobia, si comparados a los dianas $(p<0,05)$.

Palabras clave: bullying; homofobia; adolescentes. 


\section{Introdução}

No ambiente científico um tipo particular de violência escolar vem ganhando visibilidade e o que antes era compreendido como "brincadeira" hoje recebe o título de bullying - termo inglês, mas adotado e já difundido na literatura nacional. Como pontos principais, esse fenômeno pode ser caracterizado pelas ações repetitivas de abuso (físico, verbal, material ou exclusão social) na relação desigual de poder entre pares, produzindo sofrimento para aquele que é alvo da agressão. Ainda que tenha se tornado comum o seu estudo no âmbito escolar, vale ressaltar que não se trata apenas de um problema educacional, mas, principalmente, social e de saúde, uma vez que afeta diretamente a qualidade de vida e o bem-estar dos alvos.

Nas discussões sobre a conceituação do bullying, Smith (2002) destaca dois pontos como sendo os principais na caracterização dessa agressão: a repetição desses atos e a diferença de poder entre autor (aqueles que praticam o bullying) e alvo (aqueles que são vítimas da agressão). Essa diferença de poder pode ser justificada por diversos fatores, tais como o apoio recebido dos demais estudantes, a diferença de idade, de tamanho, o desenvolvimento emocional e/ou físico, dificultando a defesa do alvo (Cordeiro, Pepler, \& Craig, 2009). Além disso, Tognetta e Vinha (2010) destacam como aspecto característico dessa violência a presença de um público de testemunhas que adquirem a função de reforço para a ação do autor.

Como fenômeno social, pode-se estabelecer uma aproximação entre o bullying e o preconceito, uma vez que este último vai definir grupos mais vulneráveis a se tornarem alvos. Essa violência pode ser orientada pelo preconceito racial, religioso, regional ou ainda oriundo da diversidade sexual. Além dessas pertenças grupais, o local de origem e condições econômicas também podem ser utilizados como pretexto para o bullying, que, diferente de outras discriminações, manifesta-se de modo peculiar segundo os critérios já mencionados.

Partindo desse pressuposto, o presente trabalho realiza uma delimitação no preconceito denominado homofobia. Com efeito, é importante salientar que o conceito compartilhado no estudo em questão está para além de discriminações com pessoas que possuem relações afetivo-sexuais com outras do mesmo sexo, sendo dirigido para todos aqueles que fogem do estereótipo do dualismo masculino/feminino (Borrillo, 2009).

A homofobia é compreendida ainda como um dispositivo de regulação social que, a partir de uma construção cultural baseada na relação binária homem-mulher, legitima essa configuração como padrão para relações sexuais, afetivas e conjunturas familiares. Esse modelo baseado nas relações heterossexuais e que estigmatizam aqueles que subvertem a esse padrão recebe o nome de heteronormatividade (Teixeira-Filho, Rondini, \& Bessa, 2011).

Concordando com a perspectiva que atenta para a aproximação entre o bullying e o preconceito, Antunes (2010) chama atenção para o fato de este último tornar al- guns grupos-alvos mais vulneráveis (Antunes,\& Zuin, 2008), sendo o bullying, em alguma medida, uma das manifestações comportamentais do preconceito, se aproximando do que se chama de discriminação.

Considerando-se que "a forma como o outro é percebido define os contornos das relações interpessoais" (Salles, \& Silva, 2008, p. 150), torna-se fácil compreender como o preconceito interfere na percepção e, consequentemente, no comportamento violento.

Percebe-se que ambos os fenômenos, ou pelo menos, quando o preconceito é manifesto, parecem remeter à mesma base: a intolerância à alteridade. Assim, esse componente seria uma das bases para a agressividade denominada bullying. Essa cultura da intolerância é reforçada pela primazia do individualismo, da corrida desenfreada pelo bem-estar individual e do não reconhecimento do outro (Oliveira, \& Rosa, 2010).

Nesse cenário, o homem toma a si mesmo como modelo e estipula normas e pré-concepções que os demais devem seguir, fixando uma imagem social do outro e normas sociais rígidas. Entretanto, quando esse outro não corresponde a essas expectativas, ele se torna um problema social que "assusta e incomoda" e isso é utilizado como justificativa para atos de agressão e desrespeito (Salles, \& Silva, 2008).Contudo, embora haja algumas semelhanças entre os conceitos de bullying e o preconceito, principalmente na sua esfera comportamental, esses raramente são estudados juntos, mesmo que essa relação já tenha sido apontada como viável por outros autores (Espelage, \& Swearer, 2008).

Também deve-se destacar as diferenças entre esses fenômenos. Uma delas é o caráter mais amplo que o preconceito assume nas relações intergrupais, enquanto que o bullying ocorre mais na esfera interpessoal; o preconceito representa uma questão mais ampla presente nas mais variadas fases do desenvolvimento humano, envolvendo pessoas de diferentes gêneros, raças, idades, naturalidade e condição socioeconômicas. Noutra perspectiva, o bullying está mais voltado para a esfera comportamental, enquanto que o preconceito envolve aspectos cognitivos, afetivos e comportamentais. Por fim, a manifestação do preconceito não se limita ao bullying, ocorrendo de diversas formas.

Contudo, mesmo possuindo a intolerância como base comum, os conceitos aqui comentados não podem ser vistos como sinônimos, já que o preconceito exige uma leitura mais ampla das relações intergrupais. Além disso, a especificação de um conceito - tal como o bullying - contribui por trazer novas discussões, que até então poderiam estar sendo negligenciadas. Desta forma, ultrapassando a proposta de um conceito descritivo faz-se necessária a sua explicação a partir da comunicação com outros construtos, como estereótipos, discriminação e normas sociais.

Assim, uma vez que as normas, leis e preconceitos são fenômenos sociais, ao se pesquisar o preconceito, a discriminação e o bullying, há de se considerar o contexto no qual este ocorre: o ambiente escolar. Deve-se considerar que a escola está inserida em uma cultura mais ampla, logo, não está imune a ser um local de produção e reprodução de 
preconceitos. Torna-se, então,um desafio para a educação não apenas a alfabetização ou o ensino do conteúdo programático, mas também o ensino do respeito às diferenças.

Essa dimensão cultural e social comentada anteriormente, além de tornar mais provável à cultura da violência, pode indicar também a motivação mais frequente de bullying. Assim, tal como observado nos estudos já citados, uma vez influenciada pela norma heterossexista, a violência escolar motivada por preconceito contra homossexuais é usualmente observada (Abramovay, Cunha, \& Calaf, 2010).

Na busca por uma aproximação entre as temáticas da violência escolar - aqui especificada através do bullying - e do preconceito homofóbico, observa-se que na literatura nacional várias produções podem ser acessadas acerca da manifestação da homofobia na escola (Abramovay, Castro, \& Silva, 2004; Asinelli-luz, \& Cunha, 2011; Borges, Passamani, Ohweiler, \& Bulsing, 2011; Junqueira, 2009; Toneli, 2006). No entanto, um levantamento feito nos bancos de dados eletrônicos, realizado em julho de 2012, foi observado que quando utilizadas as palavras "bullying e homofobia" ou "bullying homofóbico", não se tem uma produção tão vasta. Nesta pesquisa foram encontrados quatro trabalhos empíricos, sendo todos em formato de resumo expandido em anais.

Foi verificado ainda que além de poucos, os estudos empíricos sobre essas temáticas são recentes, já que os trabalhos datam a partir do ano de 2010 e nenhum deles teve como fonte artigo científico publicado em periódicos. Esses trabalhos tratam, principalmente, da forma de discriminação vivenciada na escola (Silva, 2011), relação do bullying, homofobia e comportamento docente (França, \& Vieira, 2012), e forma de manifestação do bullying homofóbico, além da proposição de ações para intervir nesse cenário (Richartz, \& Santana, 2012). Diferente dessa realidade, no cenário internacional essas publicações podem ser acessadas desde a década de 90 (Douglas, Warwick, Whitty, Aggleton, \& Kemp, 1999).

Embora os estudos empíricos no âmbito nacional datem de 2010, as discussões teóricas envolvendo os termos 'bullying' e 'homofobia' são encontradas desde 2008 e as formas de publicação também ainda são, em sua maioria, os anais de congressos. Assim, fica clara a limitação de dados empíricos no contexto brasileiro que sustentem essa relação entre esses dois fenômenos. Diferente desse cenário,na literatura internacional são observados dados que demonstram uma maior vitimização entre jovens LGBTs, as consequências negativas dessa prática e o impacto positivo do suporte parental na diminuição das consequências emocionais negativas desencadeadas a partir da vivência do bullying homofóbico (António, 2011; Birkett, Espelage, \& Koenig, 2009; Hong, \& Garbarino, 2012; Méndez, 2008; Mishna, Newman, Daley, \& Solomon, 2009).

Diante dessa lacuna observada no cenário científico nacional e dada a relevância teórica e social das temáticas abordadas,o presente estudo teve como objetivo verificar empiricamente como os fenômenos de bullying e homofobia se aproximam, conhecendo como a homofobia se manifesta no meio escolar, bem como comparando a homofobia entre os diferentes atores de bullying (autor, alvo, alvo/autor e testemunhas) e se o conteúdo homofóbico é utilizado no bullying verbal, já que esta forma de violência é a mais frequente na manifestação dessa violência (Souza, 2013).

\section{Método}

O método utilizado na presente pesquisa foi quantitativo do tipo survey.

\section{Participantes}

A amostra foi composta de 808 jovens entre 12 e 18 anos, tendo sido obtida por meio do método da conveniência, muito embora critérios tenham sido estabelecidos na seleção das nove escolas em que a pesquisa foi realizada, a saber: pública estadual, possuir turmas entre o sexto ano do Ensino Fundamental e terceiro ano do Ensino Médio, ser de grande porte, estar localizada na região central da cidade e assim reunir estudantes de diferentes localidades da cidade.

A média de idade dos participantes foi de 14,9 anos (DP $=1,98)$, sendo a maioria do sexo feminino $(57 \%)$. Com relação à cor, mais da metade da amostra se definiu parda $(52 \%)$, seguido de branca $(14 \%)$, negra $(13 \%)$, indígena $(10 \%)$, amarela $(7 \%)$ e outros $4 \%$ não souberam ou optaram por não responder. A maior parte dos indivíduos afirmou professar alguma religião (93\%), sendo que $65 \%$ se afirmaram católicos e $26 \%$ evangélicos. Os demais disseram ser espíritas (8\%) ou não ter religião definida (1\%).

\section{Instrumentos}

Com a finalidade de se atingir os objetivos propostos, utilizaram-se dois instrumentos de pesquisa: um questionário contendo variáveis sociodemográficas e sobre bullying, e uma escala de homofobia manifesta e sutil.

As questões sociodemográficas faziam menção ao sexo e à idade dos participantes, além da religião, cor, série, se estes se definem como homossexual ou heterossexual, e se possuem algum familiar ou amigo próximo que é homossexual. O questionário de bullying utilizado foi uma adaptação do instrumento adotado por Bandeira (2009). O instrumento conteve 16 questões de múltipla escolha, podendo em alguns itens ser escolhida mais de uma alternativa. Esse instrumento possibilitou conhecer, através da autoafirmação de comportamentos, os papéis de bullying (classificando os participantes em alvo, autor, alvo/autor ou testemunhas), a frequência com a qual ocorre essa agressão e a motivação para ela.

A escala de homofobia manifesta e sutil foi produzida por Castillo, Rodriguez, Torres, Peres e Martel (2003) e os itens traduzidos da escala podem ser verificados em Souza (2013). A partir de uma perspectiva de estudos so- 
bre preconceito, na qual foi verificada uma mudança nesse fenômeno em consequência dos discursos de igualdade e tolerância pós segunda guerra mundial, esse instrumento busca avaliar a manifestação da homofobia em seu aspecto público de condutas hostis e de rejeição, homofobia manifesta; e em sua manifestação encoberta e camuflada, como por exemplo, a negações de emoções positivas, como simpatia e admiração pelo grupo alvo do preconceito. Esta última forma de manifestação é denominada homofobia sutil (Castillo, \& cols. 2003).

Composta por duas subescalas, ao todo o instrumento conta com 17 sentenças afirmativas - sendo dez itens sobre homofobia manifesta e sete itens representando o modo sutil. Em todos esses itens os participantes deveriam apresentar seu nível de concordância a partir de uma escala de 5 pontos de concordância ou não (discordo totalmente, discordo, nem concordo nem discordo, concordo e concordo totalmente).

Sobre os aspectos estatísticos dessa escala, foi observado que na subescala de homofobia sutil, o teste de esfericidade de Bartlett e KMO atenderam aos critérios de fatorabilidade da escala [ $\left.X^{2}(21)=852,193 ; p<0,001\right]$ e o KMO foi igual a 0,71 . Essa subescala apresentou uma confiabilidade de 0,72, verificado através do coeficiente Alfa de 0,72. Tal como descrito por Castillo e cols. (2003), a subescala de homofobia sutil compôs-se por duas dimensões: diferença de valores entre homossexuais e heterossexuais e ausência de sentimentos positivos para com os homossexuais. Os autovalores dessas dimensões foram 2,65 e 1,16; e a variância explicada por cada uma dessas foi respectivamente $37,97 \%$ e $16,51 \%$, ficando a variância total em $54,56 \%$. O teste de confiabilidade utilizado indicou coeficientes Alfa equivalentes a 0,80 e 0,65 para as dimensões 1 e 2 , respectivamente.

$\mathrm{Na}$ subescala de homofobia manifesta os seguintes valores foram encontrados $\left[K M O=0,70 ;\right.$ Bartlett; $X^{2}(15)=$ $715,801 ; p<0,001]$. Através da análise fatorial verificou-se que essa subescala se dividiu em dimensões: aceitação da condição homossexual e convivência entre homossexuais e heterossexuais. Juntas, essas dimensões explicaram $60,35 \%$ da variância dos dados, sendo $41,39 \%$ (autovalor $=$ 2,48 ) explicada pela primeira dimensão e 18,96\% (autovalor $=1,13$ ) pela segunda dimensão. Os valores obtidos pelo coeficiente Alfa foram de 0,72 para a dimensão 1 e 0,55 na dimensão 2. Quando analisados juntos todos os itens, esse valor foi de 0,71 do coeficiente Alfa.

\section{Procedimentos}

Uma vez o estudo autorizado pela Secretaria Estadual de Ensino, pelas diretorias das escolas e aprovado pelo do comitê de ética local, iniciou-se a coleta de dados. Esta se deu de modo coletivo e foi organizada em dois momentos. No primeiro dia era feito o contato inicial com os participantes, no qual era explicado aos jovens o objetivo da pesquisa e em que consistiria a sua participação. Em seguida era entregue o Termo de Consentimento Livre e Esclare- cido (TCLE) para que o participante levasse aos pais. No dia seguinte os pesquisadores retornavam às mesmas turmas e aqueles jovens que haviam trazido os termos assinados recebiam o instrumento de pesquisa para responderem naquele momento.

Antes de responder aos questionários foram fornecidos esclarecimentos necessários para essa atividade e os responsáveis pela coleta de dados ficaram presentes na sala durante a coleta a fim de responder qualquer dúvida. Destaca-se que a presente pesquisa seguiu as normas da então vigente resolução 196/96 do Conselho Nacional de Saúde acerca de pesquisas com seres humanos.

\section{Análise dos dados}

Na estatística descritiva fez-se a análise de frequência para as variáveis categóricas e para as contínuas foram calculadas médias e desvio-padrão. Na estatística inferencial se fez análises de comparação entre médias nos escores de homofobia com variáveis sociodemográficas, tendo sido conduzido o teste $t^{1}$ em relação às variáveis sexo, pertencer a alguma religião, ter contato com homossexuais. Além disso, aplicou-se a ANOVA one-way ${ }^{2}$ (teste post hoc ${ }^{3}$ LSD) na comparação entre os escores da escala de homofobia e os diferentes "papéis de bullying". O nível de significância assumido foi de $p<0,05$.

\section{Resultados}

Com base nas respostas fornecidas no questionário, foi possível organizar os participantes de acordo com sua vivência de bullying. Assim, foram identificados os quatro grupos de análise, a saber: alvo (32\%), autor (12\%), alvo/autor $(22 \%)$ e testemunha (34\%). Esses números se mostraram de forma diferenciada quando analisados separadamente entre participantes do sexo masculino e do sexo feminino. O percentual de alvos foi maior entre as meninas (36\%) se comparado aos meninos (25\%). Os meninos tiveram uma maior representação no papel de autor (18,5\%) e alvo/autor $(25,9 \%)$, sendo esse percentual significativamente inferior entre as meninas, $7,7 \%$ se identificaram como autoras e $19,3 \%$ alvos/autoras.

1 Teste $t$ - Teste estatístico que compara se existe diferença significativa entre as médias de dois grupos. $O$ teste compara se a variação entre os grupos é superior à variação que ocorre dentro de cada grupo. Com esse valor é possível verificar se a diferença nas médias se deu ao acaso ou se a variável que diferencia os grupos é realmente responsável por produzir uma diferença nas médias (Dancey, \& Reidy, 2006).

2 ANOVA one-way - teste $t$ generalizado para quando há mais de dois grupos de comparação. One-ay significa que o teste é feito com apenas um fator, ou seja, uma variável, comparado entre mais de 2 grupos (Dancey, \& Reidy, 2006).

3 Teste que compara o Erro do Tipo I. Erro do tipo I pode ser compreendido como rejeitar a Hipótese Nula de que não há relação entre as variáveis, quando ela é verdadeira (Dancey, \& Reidy, 2006). 
Embora não tenha sido o objetivo do estudo verificar diferenças entre jovens heterossexuais e homossexuais, mas sim averiguar se os autores de bullying são sujeitos mais preconceituosos do que os demais, como alguns participantes se identificaram como sendo homossexuais, verificou-se também a frequência de vitimização nesse grupo. Entre os meninos, 12 participantes se definiram homossexuais e percebeu-se entre esses meninos que o papel de alvo foi mais recorrente $(58 \%)$ do que no grupo geral dos participantes (25\%). Nenhuma menina se identificou como homossexual, logo, não foi possível verificar essa incidência no grupo.

Quanto à percepção acerca da homofobia ser a motivação para as práticas de bullying verbal, essa razão foi elencada entre os alvos como a terceira causa mais citada para as agressões ( $9 \%$ dos casos). As duas motivações mais citadas foram as características fenotípicas (67\%) e agressões de cunho racistas (10\%). As demais motivações foram a religião $(6 \%)$ e outras $(8 \%)$. Porém, quando esse dado foi analisado diferenciando homens e mulheres, as ordens de frequência se alteraram. A aparência física continua sendo a motivação mais frequente para o bullying; contudo, entre os meninos a segunda opção mais recorrente foram as ofensas de cunho homofóbico (20\%), não sendo esse preconceito comum entre as meninas ( $2 \%)$.

Outra análise realizada foi a média nos escores da escala de homofobia. O primeiro grupo comparado quanto às médias foram os sexos: meninos e meninas. Nos dados de homofobia, tanto manifesta quanto sutil, foi verificado maior preconceito entre participantes do sexo masculino, se comparado ao do sexo feminino. As meninas obtiveram média de 3,06 (DP = 0,69) na escala de homofobia sutil e 2,89 $(\mathrm{DP}=0,58)$ na escala de homofobia manifesta; enquanto os meninos pontuaram média de $3,43(\mathrm{DP}=0,62)$ na escala de homofobia sutil e 3,15 ( $D P=0,56$ ) na escala de homofobia manifesta. Além disso, ressalta-se nos intragrupos uma maior pontuação nas escalas de homofobia sutil, indicando a presença maior de uma homofobia camuflada.

Essa diferenciação entre os sexos foi considerada estatisticamente significativa segundo teste $t$, para os escores de homofobia sutil $[t(806)=7,72, p<0,001]$ e para o construto da homofobia manifesta $[t(806)=6,69, p<0,001]$; confirmando haver sim uma diferença entre os sexos, não sendo um resultado obtido ao acaso.

Outro grupo possível de comparação foi entre aqueles sujeitos que afirmaram ter amigo(a) próximo(a) ou familiar homossexual (53\% dos participantes) ou nenhum contato próximo ( $47 \%$ dos respondentes). As médias dos escores na escala de homofobia foram superiores entre aqueles sujeitos que afirmaram não possuir nenhum contato próximo com sujeitos homossexuais (homofobia manifesta 3,13 , DP = 0,56; homofobia sutil 3,37, DP $=0,66$ ), se comparado aos que possuem esse contato próximo (homofobia manifesta 2,89, DP =0,58; homofobia sutil 3,08, $\mathrm{DP}=0,67$ ). Essa diferenciação também foi confirmada com o teste $\mathrm{t}$ na homofobia manifesta $[t(806)=5,32, p<0,001]$ e nos escores de homofobia sutil $[t(806)=5,65, p<0,001]$.

Comparando os escores nas escalas de homofobia manifesta e homofobia sutil a depender do papel de bullying, observou-se que o grupo com maior homofobia manifesta foi o composto por autores de bullying $(3,2 ; \mathrm{DP}=0,56)$, seguido por alvo/autor e testemunha (ambas com média igual a 3,0 e DP igual a 0,57 e 0,62, respectivamente) e por fim, o grupo de alvos (2,9; DP = 0,59). A análise da ANOVA one-way identificou ser pouco provável que a diferença entre esses grupos se dê devido um erro amostral $[F(3,80)=5,22$ e $p<0,05]$. O teste post hoc (LSD) identificou que os autores de bullying apresentaram uma média significativamente maior do que os alvos $(p<0,00)$ e testemunhas $(p=0,05)$ de bullying na escala de homofobia. O grupo de testemunha também apresentou índices maiores de homofobia se comparado aos alvos $(p<0,05)$.

Figura 1. Comparação entre as Médias no escore de Homofobia Manifesta entre adolescentes escolares do ensino público de Aracaju-SE em função dos diferentes papéis assumidos nas situações de bullying.

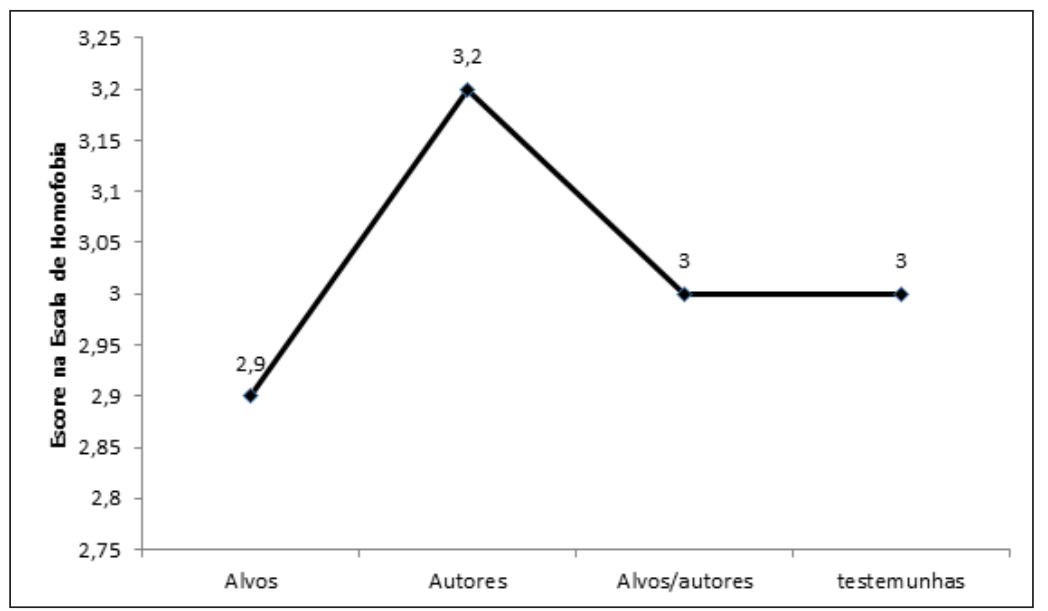

Material produzido a partir de dissertação de mestrado com financiamento do CNPq. 
Esse mesmo resultado de maior preconceito entre participantes autores de bullying foi verificado na homofobia sutil $(3,4 ; \mathrm{DP}=0,68)$, seguido de alvo/autores $(3,2 ; \mathrm{DP}=$ $0,70)$ e testemunhas $(3,2$; DP $=0,69)$, e por fim os alvos $(3,1$; $\mathrm{DP}=0,67)$, essa diferença também não foi ao acaso $[\mathrm{F}(3,80)$ $=3,73$ e $p<0,01]$.Os autores mais uma vez apresentaram um escore significativamente superior aos grupos de testemunha $(p<0,05)$ e alvo $(p<0,01)$.

\section{Discussão}

Segundo os resultados apresentados, os grupos que apresentam maiores escores nas subescalas de homofobia, tanto manifesta quanto sutil, são os participantes do gênero masculino, aqueles que afirmam não possuir contato próximo com homossexuais e autores de bullying. Em estudo nacional com escolares da rede pública de diversos estados brasileiros um dado semelhante é observado (Abramovay, \& cols., 2010). Analisando por sexo, nota-se que os meninos são percebidos como mais preconceituosos $(44,4 \%$ dos participantes) do que as meninas (14,9\% da amostra). Esse mesmo resultado de diferenciação entre os sexos foi observado em estudo realizado por Cerqueira-Santos, Winter, Salles, Longo e Teodoro (2007).

No que tange à variável "contato com homossexuais", os participantes do gênero masculino são frequentemente identificados como mais preconceituosos e menos propensos à amizade com um estudante de minoria sexual (Poteat \& DiGiovanni, 2010; Poteat, Espelage, \& Koenig, 2009). Contudo, segundo Cerqueira-Santos e cols. (2007), quando sujeitos de ambos os gêneros possuem algum tipo de relacionamento interpessoal próximo, é anulada a interferência da variável sexo, não havendo diferenças entre homens e mulheres. A partir desta pesquisa pode ser ressaltada a necessidade de se promover o contato entre os grupos, a fim de se rever os estereótipos, preconceitos e, consequentemente, a violência.

Considerando os dados acima e tendo a escola como um dos ambientes mais importantes de socialização entre pares adolescentes, esse local pode ser cenário de intervenções que visem o relacionamento com grupos minoritários. Para isso, a escola precisa assumir a diversidade existente nela e não mais desconsiderar a diversidade sexual existente nesse espaço (Louro, 2007). Destaca-se ainda o período de desenvolvimento no qual se encontram os participantes. É nessafase que ocorrem as principais mudanças corporais, como alteração na voz entre os meninos, espinhas, crescimento acelerado e outras, que os tornam distantes do padrão idealizado e compartilhado socialmente.

Como destacado por Mahan e cols (2006), o bullying geralmente se apropria de motivos externos ao sujeito que podem facilmente ser percebidos e por essa razão as características fenotípicas como altura e peso são os principais conteúdos do bullying. Porém, não é apenas um modelo de beleza que orienta esses comportamentos violentos, mas também comportamentos manifestos que fujam ao estereótipo de gênero compartilhado.Mahan e cols. (2006) desta- cam assim os trejeitos como sendo a principal motivação para o bullying, independente da orientação sexual do aluno. $\mathrm{Na}$ presente pesquisa, os trejeitos e as palavras de cunho homofóbico são o segundo motivo para manifestação de bullying entre os participantes do sexo masculino. Entre as meninas essa porcentagem está quase ausente.

Esses dados também estão em consonância com pesquisa realizada por Swearer, Turner, Givens e Pollack (2008), no qual foi observado que em $26 \%$ dos casos de bullying entre meninos, nota-se uma associação entre essa violência e a homofobia, já que os alvos relatam a cena como uma agressão verbal na qual são chamados de gay. Uma forma de compreender essa diferença entre os gêneros pode ser a partir da leitura de que os homens estariam indo de encontro a duas normas sociais: a heteronormatividade e o modelo hegemônico de masculinidade (Daley, Solomon, Newman, \& Mishna, 2008), pois estariam portando características não valorizadas socialmente (ditas femininas), enquanto que as mulheres estariam transgredindo apenas a heteronormatividade, já que foi dado a elas, a partir das lutas dos grupos feministas, conquistarem as características masculinas de atividade e racionalidade. Assim, juntamente à valorização da masculinidade, há uma desvalorização das mulheres e o sentimento de antifeminino como elementos fundamentais na homofobia (Daley, \& cols., 2008).

A expansão da compreensão da homofobia para além da violência dirigida para pessoas que possuem uma relação com sujeitos do mesmo sexo, afetando todos aqueles que possuem uma característica socialmente determinada como sendo do sexo oposto (Borrillo, 2009), leva-nos a compreensão do porquê na presente pesquisa participantes que se definem heterossexuais são alvos de um bullying homofóbico. Essa mesma leitura leva-nos a compreender porque isso ocorre de modo mais frequente entre meninos. Segundo Daley e cols. (2008) esse fato pode ser refletido por meio da luta histórica na qual o movimento feminista parece ter ampliado a compreensão acerca do que é ser mulher e buscado romper com a rigidez nos estereótipos. Isto pode explicar a menor vitimizaçãodas mulheres com termos homofóbicos.

Segundo Swearer e cols. (2008), ao se considerar alvo de bullying por ser chamado de gay, o significado que vem implicado nisso é o de ser um indivíduo "defeituoso", já que essa é a percepção que se tem das pessoas homossexuais; logo, tais termos são considerados ofensas. Pode-se ir mais além, e ver que a compreensão dessa linguagem se torna ofensiva também na medida em que o alvo compreende a homossexualidade como algo negativo, visto que, para pessoas que não compreendem assim, ser comparados a homossexuais pode não ter o mesmo impacto. Um dado que pode exemplificar essa hipótese é apresentado por Swearer e cols. (2008), no qual $86 \%$ dos estudantes heterossexuais, distribuídos semelhantemente entre homens e mulheres, afirmaram que ficariam chateados se fossem identificados pelos pares como homossexuais.

Na pesquisa realizada por Abramovay e cols. (2010), a discriminação pela pessoa ser ou parecer homossexual 
correspondeu a $63,1 \%$ dos casos na escola, representando um dado expressivo. Nessa mesma pesquisa, 33\% dos jovens relataram ter sofrido violência verbal ou física em virtude da sua orientação sexual real ou percebida. Outros estudos na área demonstram também uma maior vitimização entre jovens LGBTs se comparados a jovens heterossexuais, o que reforça a relação entre homofobia e bullying (Berlan, Corliss, Field, Goodman, \& Austin, 2010; Friedman e cols. 2011; Rivers, 2001). Contudo, a homofobia, percebida hoje como um fenômeno recorrente no contexto escolar (Mahan e cols., 2006), ainda é pouco associada com bullying nos estudos científicos nacionais, muito embora, assim como nos resultados deste artigo, Poteat (2008) já havia sinalizado que jovens autores de bullying também apresentam altos níveis de atitudes negativas contra a juventude LGBT, além de uma maior utilização de termos homofóbicos. Esses alunos mais preconceituosos tendem a usar mais conteúdos homofóbicos ao praticar o bullying, se comparados a outros autores que exibemmenor preconceito (Poteat, \& DiGiovanni, 2010).

$\mathrm{Na}$ relação entre bullying e homofobia, o autor da violência tem como intuito dominar o alvo e, para isso, usa recursos que socialmente são considerados hierárquicos, como a orientação sexual. Chamar o outro de homossexual é colocá-lo em um patamar considerado por esses autores como inferiores, já que o preconceito produz nas relações interpessoais um comportamento de ênfase na posição social dos grupos, no qual o grupo de pertencimento é percebido como superior ao grupo discriminado (Lima, 2011). Por dominância compreende-se as tentativas de estabelecer ou perpetuar as hierarquias, em quealguns indivíduos têmmaior acesso a recursos e são considerados com maiorstatus, influência ou controle sobre outros pares (Poteat, \& DiGiovanni, 2010).Tem-se portanto que, como um meio de intimidação, o bullying homofóbico afeta a todos, independentemente da orientação sexual (DePalma,\& Jennett, 2010; Horn, 2007), já que conforme observado por Hong e Garbarino (2012) entre adolescentes a aceitabilidade de seus paresnão esta relacionada somente à orientação sexual, mas principalmente à conformidade às normas de gênero.

Destaca-se a complexidade dos fenômenos aqui investigados, em que, para compreender o bullying, fez-se necessário buscar outros fenômenos macrossociais - como a heteronormatividade e o sexismo -, a fim de se ampliar uma leitura da realidade e verificar que o bullying e o preconceito podem não ocorrer isoladamente. Além disso, tratam-se de temáticas relevantes que se entrelaçam com a educação, o social e o bem-estar dos jovens, afirmando a necessidade de se abordá-las.

\section{Considerações Finais}

Conforme observado nos reultados do presente estudo, o bullying é uma problemática bastante recorrente no contexto escolar investigado, envolvendo32\% dos estudantes em papéis de alvos de bullying, $12 \%$ como autores, $22 \%$ em ambos os papéis de alvo e autor e $34 \%$ somente como testemunhas. Na relação com a homofobia, a presença de conteúdos dessa natureza no bullying verbal é preponderante entre os participantes do sexo masculino, em $20 \%$ dos casos de bullying, enquanto que entre as adolescentes do sexo feminino essa incidência foi pouco observada, apenas $2 \%$ dos casos. Além disso, os autores de bullying apresentaram maiores escores na escala de homofobia, se comparado aos alvos, o que indica uma relação entre a autoria e essa forma de violência escolar $(p<0,05)$.

Diante dos resultados e do bullying homofóbico estar dirigido aoutros estudantes que não apenas os que se autodenominaram homossexuais, percebe-se que o maior desafio para a prevenção de bullying homofóbico parece ser a abordagem da masculinidade hegemônicae da heteronormatividade no contexto escolar, uma vez que para além do tipo de relação afetivossexual estabelecida pelos jovens, evidencia-se a influência dos esterótipos do "ser homem" e "ser mulher" nesse contexto cultural investigado.

Como limitação do presente estudo observa-se o número reduzido de participantes que se definem homossexuais, o que impossibilita comparar se nesse grupo ocorre uma maior vitimização do que entre estudantes heterossexuais. Desta forma, sugere-se que novos estudos busquem ativamente esse grupo, a fim de ter uma maior representação na amostra, o que possibilitará análises diferenciadas da ocorrência de bullying em tais grupos.

\section{Referências}

Abramovay, M., Castro, M. G., \& Silva, L. B. (2004). Juventude e sexualidade. Brasília: UNESCO Brasil.

Abramovay, M., Cunha, A. N., \& Calaf, P. P. (2010). Revelando tramas, descobrindo segredos: violência e convivência nas escolas ( $2^{\mathrm{a} e d}$.). Brasília: Rede de Informação Tecnológica Latino-americana [RITLA], \& Secretaria de Estado de Educação do Distrito Federal [SEEDF].

Asinelli-Luz, A., \& Cunha, J. M. (2011). Percepções sobre a discriminação homofóbica entre concluintes do Ensino Médio no Brasil entre 2004 e 2008. Educar em Revista, 39, 87-102.

António, A. R. B. M. J. (2011). O Papel Moderador do Suporte Parental e Social no Efeito do Bullying Homofóbico nas Consequências Psicológicas para os Jovens. Dissertação de mestrado, Instituto Universitário de Lisboa, Lisboa, Portugal.

Antunes, D. C. ,\& Zuin, A. A. S. (2008). Do bullying ao preconceito: Os desafios da barbárie à educação. Psicologia e Sociedade, 20, 33-42.

Antunes, D. C. (2010). Bullying, razão instrumental e preconceito. São Paulo: Casa do Psicólogo.

Bandeira, C. M. (2009). Bullying: Auto-Estima e diferenças de gênero. Dissertação de Mestrado, Universidade Federal do Rio Grande do Sul, Porto Alegre-RS. 
Berlan, E. D., Corliss, H. L., Field, A. E., Goodman, E., \& Austin, S. B. (2010).Sexual orientation and bullying among adolescents in the growing up today study. Journal of Adolescent Health, 46, 366-371.

Birkett, M., Espelage, D. L., \& Koenig, B. (2009). LGB and questioning students in schools: The moderating effects of homophobic bullying and school climate on negative outcomes. Journal of Youth Adolescence, 38, 989-1000.

Borges, Z. N., Passamani, G. R., Ohlweiler, M. I., \& Bulsing, M. (2011). Percepção de professoras de ensino médio e fundamental sobre a homofobia na escola em Santa Maria (Rio Grande do Sul/Brasil). Educar em Revista, 39, 21-38.

Borrillo, D. (2009). A Homofobia. Em T. Lionço, \& D. Diniz (Orgs), Homofobia \& Educação: um desafio ao silêncio (pp.15-46). Brasília: Letras Livres EdUnB.

Castillo, M. N. Q., Rodriguez, V. B., Torres, R. R., Pérez, A. R., \& Martel, E.C. (2003). La medida de la homofobia manifesta y sutil. Psicothema, 15(2), 197-204.

Cerqueira-Santos, E.,Winter, F. S., Salles, L. A., Longo, J. L., \& Teodoro, M. L. M. (2007). Contato Interpessoal e Crenças sobre Homossexualidade: Desenvolvimento de uma Escala. Interação em Psicologia, 11(2), 221-229.

Cordeiro, J., Pepler, D. J., \& Craig, W. (2009). Abordagem para o bullying e vitimização. Canadian Family Physician - Le Médecin de famille canadien, 55, 356-360.

Daley, A., Solomon, S., Newman, P. A., \& Mishna, F. (2008).Traversing the Margins: Intersectionalities in the Bullying of Lesbian, Gay, Bisexual and Transgender Youth. Journal of gay \& lesbian social services, 19(3), 9-29.

Dancey, C. P. \& Reidy, J. (2006). Estatística Sem Matemática Para Psicologia. Porto Alegre: Artmed.

DePalma, R., \& Jennett, M. (2010). Homophobia, transphobia and culture: Deconstructing heteronormativity in English primary schools. Intercultural Education, 21, 15-26.

Douglas, N., Warwick, I., Whitty, G., Aggleton, P., \& Kemp, S. (1999). Homophobic bullying in secondary schools in England and Wales teachers' experiences. Health Education, 99(2), 53-60.

Espelage, D. L., \& Swearer, S. M. (2008).Addressing research gap in the intersection between homophobia and bullying. School Psychology Review, 37(2), 155-159.

França, F. G. R., \& Vieira, P. L. (2012). Os professores de educação física frente ao bullying homofóbico na escola. Em Associação Brasileira de Estudos de Homofobia (Org.), VI Congresso Internacional de Estudos Sobre a Diversidade Sexual e de Gênero. Salvador-BA: ABEH.
Friedman, M. S., Marshal, M.P., Guadamuz, T. E., Wei, C., Wong, C. F., \& Saewic, E. M. (2011). A metaanalysis of disparities in childhood sexual abuse, parental physical abuse, and peer victimization among sexual minority and sexual nonminority individuals. American Journal of Public Health, 101, 1481-1494.

Hong, J. S., \& Garbarino, J. (2012). Risk and Protective Factors for Homophobic bullying in schools: an application of the socialecological framework. Revista Education Psychology, 24, 271285.

Horn, S. S. (2007). Adolescents' acceptance of same-sex peers based on sexual orientation and gender expression. Journal of Youth and Adolescence, 36, 363-371.

Junqueira, R. D. (2009). Diversidade sexual na educação: problematizações sobre a homofobia nas escolas. Brasília: MEC/ UNESCO.

Lima, M. E. O (2011). Preconceito. Em L. Camino, A. R. R. Torres, M. E. O. Lima, \& M. E. Pereira (Orgs.), Psicologia Social: temas e teorias (pp. 451-500). Brasília: Technopolitik.

Louro, G. L. (2007). O corpo educado: pedagogias da sexualidade (2a ed.) Belo Horizonte: Autêntica.

Mahan, W. C., Varjas, K., Dew, B. J., Meyers, J., Singh, A. A., Marshall, M. L., \& Graybill, E. C. (2006).School and Community Service Providers' Perspectives on Gay, Lesbian and Questioning Bullying. Journal of LGBT Issues in Counseling, 1(2), 45-66.

Méndez, P. (2008). La homofobia como elemento clave del acoso escolar homofóbico. Algunas voces desde Rivas Vaciamadrid, 94, 71-83.

Mishna, F., Newman, P. A., Daley, A., \& Solomon, S. (2009). Bullying of Lesbian and Gay Youth: A Qualitative Investigation. The British Journal of Social Work, 39, 1598-1614.

Oliveira, M. B., \& Rosa, E. M. (2010). Juventude, violência e alteridade. Temas em Psicologia, 18, 113-121.

Poteat, V. P. (2008). Contextual and moderating effects of the peer group climate on use of homophobic epithets. School Psychology Review, 37(2), 188-201.

Poteat, V. P., Espelage, D. L., \& Koenig, B. W. (2009). Willingness to remain friends and attend school with lesbian and gay peers: Relational expressions of prejudice among heterosexual youth. Journal of Youth and Adolescence, 38, 952-962.

Poteat, V. P., \& DiGiovanni, C. D. (2010). When Biased Language Use is Associated With Bullying and Dominance Behavior: The Moderating Effect of Prejudice. Journal Youth Adolescence, 39, 1123-1133. 
Richartz, T., \& Santana, Z. (2012). A heteronormatividade e o bullying: análise das medidas educativas adotadas por supervisores escolares para coibir a homofobia praticada por alunos do Ensino Fundamental I. Em Associação Brasileira de Estudos de Homofobia (Org.), VI Congresso Internacional de Estudos Sobre a Diversidade Sexual e de Gênero. Salvador-BA: ABEH.

Rivers, I. (2001). The bullying of sexual minorities at school: Its nature and long-term correlates. Educational and Child Psychology, 18, 32-46.

Salles, L. M. F., \& Silva, J. M. A. P. (2008). Diferenças, Preconceito e Violência no âmbito escolar: algumas reflexões. Cadernos de Educação, 30, 149-166.

Silva, P. T. B. (2011). Bullying homofóbico: reminiscências de jovens homossexuais da educação básica do município de Teixeira de Freitas-Bahia. Em Anais do II Seminário Internacional Enlaçando Sexualidades. Salvador- BA: UNEB.

Smith, P. K. (2002). Intimidação por colegas e maneiras de evitá-las. Em E. Debarbieux, \& C. Blaya (Orgs.), Violências nas escolas e políticas públicas (pp. 184-205).Brasília: UNESCO.
Souza, J. M. (2013). Bullying: Uma das faces do preconceito homofóbico entre jovens no contexto escolar. Dissertação de Mestrado, Universidade Federal de Sergipe, Aracaju-SE.

Swearer, S. M., Turner, R. K., Givens, J. E.,\& Pollack, W. S. (2008). "You're so gay!": Do different forms of bullying matter for adolescent males? School Psychology Review, 37, 160-173.

Teixeira-Filho, F. S., Rondini, C. A., \& Bessa, J. C. (2011). Reflexões sobre homofobia e educação em escolas do interior paulista. Educação e Pesquisa, 37(4), 725-742.

Tognetta, L. R. P., \& Vinha, T. P. (2010). Bullying e intervenção no Brasil: um problema ainda sem solução. Em Instituto Universitário (Org.), Actas do $8^{\circ}$ Congresso Nacional de Psicologia da Saúde: Saúde, sexualidade e gênero. Lisboa, Portugal: ISPA.

Toneli, M. J. F. (2006). Homofobia em contextos jovens urbanos: contribuições dos estudos de gêneros. Revista de Psicologia da Vetor Editorial, 7(2), 31-38.

\section{Sobre os autores}

Jackeline Maria de Souza (jackeline.souza1@gmail.com) Mestre em Psicologia Social pela Universidade Federal de Sergipe (UFS). Docente substituta da Universidade Federal do Vale do São Francisco (UNIVASF).

Joilson Pereira da Silva (joilsonp@hotmail.com)

Doutor em Psicologia pela UniversidadComplutense de Madrid, Espanha.

Docente Adjunto II da Universidade Federal de Sergipe (UFS).

André Faro Santos (Andrefaro@superig.com.br)

Doutor em Psicologia pela Universidade Federal da Bahia (UFBA).

Docente da Universidade Federal de Sergipe (UFS). 
